\title{
The Role and Mechanism of SIPR5 in Colon Cancer
}

This article was published in the following Dove Press journal:

Cancer Management and Research

\author{
Huijun Zhou' \\ Xianli Yin ${ }^{2}$ \\ Fei $\mathrm{Bai}^{3}$ \\ Wu $\mathrm{Liu}^{2}$ \\ Shaofeng Jiang ${ }^{2}$ \\ Jinfeng Zhao'
}

'Key Laboratory of Nanobiological Technology of National Health

Commission of China, Xiangya Hospital,

Central South University, Changsha,

Hunan, People's Republic of China;

${ }^{2}$ Department of Gastroenterology and

Urology, Hunan Cancer Hospital \& the

Affiliated Hospital of Xiangya School of

Medicine, Central South University,

Changsha 410013, Hunan, People's

Republic of China; ${ }^{3}$ Department of

Gastroduodeno Pancreatic Surgery,

Hunan Cancer Hospital \& the Affiliated

Hospital of Xiangya School of Medicine,

Central South University, Changsha

4I00I3, Hunan, People's Republic of

China
Purpose: To investigate the role and mechanism of S1PR5 in colmeancer.

Materials and Methods: Lentiviral infection and drug scre ng helpo to establish colon cancer cell lines with stable overexpression and knockdo of S1PR5. 1 ects of S1PR5 expression on cell growth, proliferation, migration nd in cion were nalyzed using a subcutaneous xenograft model in nude mice. W ern blot (W was sed to detect the effects of S1PR5 expression on p-AKT, STAT3 F-KB, a p-JNK. distribution of $\mathrm{p} 65$ was evaluated in nuclear and cytoplasmic fr tion and Transwell invasion assays analyzed 11 growth, - lifere migration, and invasion. qRT-PCR analysis revealed that S1P o c ession was ociated with altered expression levels of NF-kB downstream target genes, suo is IL-6, TNF- $\alpha$, and indoleamine 2, 3-dioxygenase 1 (IDO1).

Results: qRT-PCR and WF nalysis showed that the S1PR5 level in colon cancer cell linesSW480, SW620, HCT116, nd LoVo-w significantly higher than in NCM460, a healthy colonic epithelial cell line. V620 and N480, with high and low expression of S1PR5, respectively, we ched as lines. S1PR5 knockdown in SW620 caused the growth rate, prol ration ration, invasion, and subcutaneous tumor formation rate to decrease in mice, or s S1PRs overexpression in SW480 caused all of these parameters to in ase. $\mathrm{YB}$ ana is showed an increase in phospho-p65 and its nuclear translocation. $S$ R5 kno down ca d a decrease in phospho-p65 levels and its nuclear import, thereby in tin as actm S1PR5 knockdown and overexpressing cells, p65 was overexpressed and k, ked down, respectively. qRT-PCR and WB showed that S1PR5 over-expression upregulates $\mathrm{Q}$ 1, and S1PR5 knockdown inhibits IDO1. CCK-8 and Transwell assays showed hat p65 and IDO1 overexpression antagonizes the antitumor effect of S1PR5 knockdown, and th. 65 and IDO1 knockdown antagonizes the tumorigenic effect of S1PR5 overexpression. Conclusion: S1PR5 overexpression promotes the growth, migration, and invasion of cancer by activating the NF- $\mathrm{KB} / \mathrm{IDO} 1$ signaling pathway.

Keywords: S1PR5, NF- $\mathrm{B}$, IDO1, colon cancer

\section{Introduction}

Colon cancer is a high-incidence malignant tumor of the digestive tract. It ranks third in the world amongst malignant tumors, and fourth in terms of mortality. The incidence of colon cancer is higher in developed western countries; however, with the rapid economic growth that developing countries are experiencing, which is leading to improved standards of living, westernized diet structures, and schedule prevalence, the incidence of colon cancer in developing countries is rising rapidly as well. ${ }^{1}$

Epidemiological studies show that genetic factors, inflammatory bowel disease, eating habits, consumption of alcohol, and smoking are risk factors for colon cancer. $^{2}$ From a mechanical point of view, the high-risk factors for colon cancer
Key Laboratory of Nanobiological

Technology of National Health

Commission of China, Xiangya Hospital,

Central South University, No. 87 Xiangya

Road, Kaifu District, Changsha, Hunan

410008 , People's Republic of China

Tel +86-I 5874856567

Email 447620788@qq.com 
and the imbalance of intestinal homeostasis contribute to the formation of inflammatory and immunosuppressive microenvironments that encourage the malignant transformation of cells. For example, exposure to long-term risk factors can change the composition and distribution of the intestinal microbiome and promote the survival of proinflammatory microorganisms, thereby forming an immunosuppressive microenvironment in which small molecules, such as inflammatory factors, can act as ligands. On interaction with the cell surface receptors of intestinal epithelial cells, the regulatory signals are altered, reshaping cellular gene expression and metabolism, and eventually leading to malignant transformation of the cells. Cell surface receptors are key mediating factors for the interaction between the microenvironment and the cell. Changes in the composition and distribution of cell surface receptors are required for malignant changes to occur and for microenvironmental information to adapt to the microenvironment. Numerous studies have shown that targeted therapies and immunotherapeutic techniques based on surface receptors, such as EGFR, PD-1, and CART, play an important role in the treatment of malignant tumors, including colon cancer. ${ }^{3}$ Therefore, it is important to identify the receptors that impact the development of col cancer, develop new therapeutic targets, and reduce th risk of resistance to individual drugs.

During the course of treatment, the side-ects of ised by anti-cancer drugs limit their use; at an same tumors are prone to drug resistance. $C$ irent, cere is no effective solution to this problem owever, th discovery of S1PR regulators bring new eas for porential solutions. S1PR1 is the fi cloned S1 gene; it was discovered and cloned 1990wwile researchers were screening for key gen invo din the early differentiation of endother celn In th following decade, S1PR2, S1Pp, S1P 4, an S' R5 were successively discovered nd clo 1 The distribution of S1PRs in different tissu different; however, they are the most highly expressea cells with immune functionality. ${ }^{6,7}$ This discovery first revealed the role of S1PRs in immune regulation. Inhibitors against all S1PRs or particular S1PRs have been developed; some have been used as immunomodulators in clinical applications, such as Fingolimod, which combines with S1PR1, 3, 4, and 5. Fingolimod has been approved by the US FDA to treat multiple sclerosis. ${ }^{8,9}$ As the key role of S1P in the regulation of tumors has been revealed, the role of S1PRs in tumors is beginning to be understood. RNA interference and gene knockout studies in cell lines and mouse models have revealed the roles of S1PRs in tumor growth, invasion, and angiogenesis-related metastasis. ${ }^{10-12}$ Studies have shown that S1PRs exert their effects on tumors in a tissue-specific manner. Thus, the specific roles and mechanisms of S1PRs in different tissue types can be utilized for the development of new therapeutic techniques. Although studies have confirmed that S1P is closely related to colon cancer development, the expression level, function, and mechanism of S1PRs in colon cancer have not been reported.

The comprehensive role of Sy in infla natory and immune microenvironments and existing i earch on S1PRs indicate that S1PRs ay pla n impor int role in cancers, especially tho associoted th Alammation, such as colon cancer. arefo, S1PR5, which is significantly elevated ip olon ca er, was mer over-expressed or knocked $\mathrm{d}$ in colon ca lines, and its function and mechanisu vere studied at the cellular and animal le Shis study help to reveal the pathogenesis of $c$ on cancer and provide the basis for using S1PR5 as a ta fet for diagi sing and treating colon cancer.

\section{Matern.. and Methods} N $\mathrm{u}$. $\mathrm{d}$ and Instrument

reagents

eagents for this study included: TRIzol reagent (Thermo isher Scientific, USA), citrate buffer $(\mathrm{pH}=6.0)$ (Wuhan Boshide Corporation, China), qSYBR Green PCR kit (Shanghai GenePharma, Shanghai, China), reverse reaction kit (Promega, USA), 10×RT buffer (Dalian Bao Biotech Company, China), DEPC water (Sigma-Aldrich, USA), MMLV reverse transcriptase (Dalian Bao Biotech Company, China), $2.5 \mathrm{mM}$ dNTP mixture (Nanjing Kaiji Biotech., China), 10× PCR buffer (Promega, USA), fetal bovine serum (Thermo Fisher Scientific, USA), trypsin/ EDTA (Thermo Fisher Scientific, USA), Transwell chamber (Merck, USA), Lipofectamine TM 2000 (Thermo Fisher Scientific, USA), CCK-8 (Tongren Chemical Research Institute, Japan), Annexin V-FITC Apoptosis Detection Kit (Promega, USA), and RPMI-1640 medium (Life Technologies, Gaithersburg, MD).

\section{Instruments}

Instruments for this study included: a thermostatic magnetic stirrer (Jiangsu Jintan Medical Instrument Co., Ltd., China), an oven (Jiangsu Jintan Medical Instrument Co., Ltd., China), a low temperature high speed centrifuge 
(Sigma-Aldrich, USA), an incubator (Sigma-Aldrich, USA), an Olympus optical microscope (Olympus Corporation, Japan), a carbon dioxide incubator (Sanyo Co., Japan), an FE-20 pH meter (Mitler, Switzerland), a DK-2000-IIIL constant temperature water bath (Tianjin Test Instrument Factory, China), an SOP 62-0025 Pure water meter (Millipore, USA), a 7500 fluorescence quantitative PCR instrument (ABI, USA), a flow cytometer (BD Biosciences, USA), pipettes (Eppendorf, Germany), a micro high-speed benchtop cryogenic centrifuge (SigmaAldrich, USA), and BCLB/C nude mice (Slyke Jingda company, Hunan, China).

\section{Experimental Method Specimen Sources}

All samples in this study were derived from cancer tissues and the corresponding paracancer tissues (no less than $2 \mathrm{~cm}$ from the tumor edge) of 98 colon cancer patients who received surgical treatment in the affiliated cancer hospital, Xiangya Medical College of Central South University, from January 2017 to December 2017. The human tissue samples collected and used for testing were approved by the informed consent of the patients and the ethics committee of the affiliated cancer hospital, X Medical College of Central South University.

\section{Cell Experiment}

Four colon cancer cell lines, SW480

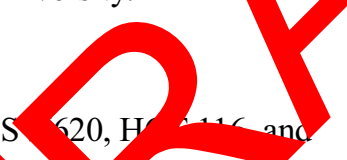

LoVo, and a healthy colonic epi aral co ne, NCM460 (Shanghai institute of cell b v, Chineso cademy of sciences), were selected for t.e study The cells were cultured in RPMI 1640 mediur (Life Techno- ies, Gaithersburg, MD), containing 10 fetal vvine serum (Thermo Fisher Scientific, USA) an $100 \mathrm{~mL}$ strentomycin, in an incubator (Sigma- $A$, US at $37 \%$ and $5 \% \mathrm{CO}_{2}$.

Establ ment the Subcutaneous Xenograft Model SW480/N sW480/S1PR5, SW620/NC, and SW620/ shS1PR5 wer ultured to logarithmic growth phase, trypsinized, and counted. Fetal bovine serum (Thermo Fisher Scientific, USA), trypsin/EDTA (Thermo Fisher Scientific, USA), RPMI-1640 medium (Life Technologies, Gaithersburg, MD), and $2 \times 10^{6}$ cells were injected into approximately 5-week-old female nude mice (BCLB/C nude mice, Slyke Jingda company, Hunan, China). Tumor growth was monitored every third day, and the long and short diameters of the tumor were recorded. After 21 days, the nude mice were sacrificed using the routine procedure, the tumors were photographed and weighed, and the subcutaneous tumors were fixed with paraformaldehyde after being photographed. Log phase cells were collected and resuspended in the medium after centrifugation, and the concentration of the cell suspension was adjusted by adding $100 \mu \mathrm{L}$ of complete medium to each well. Thereafter, the density of the cells to be tested was adjusted to 4000 cells per well, sterile PBS was added to the wells, and the cells were incubated in a $37{ }^{\circ} \mathrm{C}$ incubator with $5 \% \mathrm{CO}_{2}$. Subsequently, $100 \mu \mathrm{L}$ of fresh medium was added to each well at $0,12,24$, 48 , and $72 \mathrm{~h}$. Three wells with 100 cell culture medium alone were used as blank con ${ }^{+}$S. Afte ding $10 \mu \mathrm{L}$ of CCK-8 (Tongren Chemical K earch Institu Japan) solution to each well, incub on wa ontinue for $0.5-4 \mathrm{~h}$ in a cell culture incubat . Initially deto with a microplate reader was conduch at $0.5,2$, and $4 \mathrm{~h}$. Thereafter, suitable time points $\mathrm{w}$ select or meas ing the absorbance range for the ne rexperime absorbance (OD value) of each worl was termined at $450 \mathrm{~nm}$ on the microplate re a value of each group was calculated $y$ repeating the experiment thrice.

\section{asion Ex eriment}

The nus of was removed from the $-20^{\circ} \mathrm{C}$ refrigerator and 1. 4 at $4{ }^{\circ} \mathrm{C}$ before being transferred to a clean bench. The matrigel was diluted with serum-free medium $(1: 8=$ matrigel:medium) and added to the upper chamber of a 24well Transwell chamber, which was placed at $4{ }^{\circ} \mathrm{C}$ overnight and then kept at room temperature for $30 \mathrm{~min}$ the next day. The residual liquid in the culture plate was aspirated, $50 \mu \mathrm{L}$ of serum-free medium containing $10 \mathrm{~g} / \mathrm{LBSA}$ was added to each well, and the cells were serum-starved for $12-24 \mathrm{~h}$ at $37^{\circ} \mathrm{C}$ for $30 \mathrm{~min}$ to remove the effect of serum before the cell suspension was prepared. The transfected experimental and negative control group SW480 and SW620 cells were trypsinized, resuspended, and counted. A total of $200 \times$ liters of cell suspension containing $2 \times 10^{5}$ cells was added to the upper chamber of the Transwell unit, and $600 \mu \mathrm{L}$ of DMEM medium, containing 20\% FBS, was added to the lower chamber. Following incubation for $2 \mathrm{~h}$ at $37{ }^{\circ} \mathrm{C}$ in a $\mathrm{CO}_{2}$ incubator, the Transwell chamber was rinsed thrice with $\mathrm{PBS}$, and 4\% paraformaldehyde was used to fix cells at room temperature for $30 \mathrm{~min}$. Thereafter, the matrigel and the tumor cells in the upper chamber were gently wiped off with a cotton swab and stained with $0.1 \%$ crystal violet for $20 \mathrm{~min}$. Excess crystal violet was washed off with water, and the Transwell chamber was oven dried. Photographs were taken using an 
upright light microscope, and nine fields were randomly chosen for cell counts. The experiment was repeated three times, independently.

\section{Western Blot}

The cells cultured to logarithmic growth phase were scraped off, and $1 \mathrm{~mL}$ lysate was used following homogenization. After $30 \mathrm{~min}$, the supernatant was collected by centrifugation (Sigma-Aldrich, USA) at 12,000 rpm for 10 min. The protein concentration of each tube was measured by the BCA method and adjusted with the loading buffer. A total of $20 \mu \mathrm{g}$ of protein was mixed with SDS buffer, denatured at $95{ }^{\circ} \mathrm{C}$ for $5 \mathrm{~min}$, and electrophoresed on a $10 \%$ SDS-PAGE gel. The protein sample and the gel loading buffer were mixed at a volume ratio of $4: 1$, boiled, and denatured on an electric furnace. After cooling to room temperature, $40 \mu \mathrm{g}$ of protein sample was loaded onto each lane. The electrophoresis buffer was added to the electrophoresis tank, and the samples were electrophoresed. When the bromophenol blue dye indicator reached the bottom of the separation gel, the power supply was disconnected. The gel was removed from the electrophoresis tank, immersed in the transfer buffer for half an hour to equilibrate, and electrophoresed for about $60 \mathrm{~min}$. The membra was removed, stained with Ponceau for $5 \mathrm{~min}$, and rinse with TBST. Thereafter, the membrane was red in a hybridization bag with $5 \%$ skim milk pe der so tion as the blocking agent and then incubated a pom to ture for $1 \mathrm{~h}$ with gentle shaking. After cmovi blocking solution, appropriately dil primary tibody (S1PR5 1:500) was added to we me rane, whior was sealed after removing air obles and in bated at $4{ }^{\circ} \mathrm{C}$ overnight. Subsequently the filte was rinsed thrice with BST for $10 \mathrm{~min}$ and phed in hybridization bag, and the corresponding se ary a ady la led with horseradish peroxidase (2 1 -rabb $\mathrm{IgG} \mathrm{h}$ was added at $0.1 \mathrm{~mL} /$ $\mathrm{cm}^{2}$. After novin mubbles, the membrane was incubated at room aperature for $1 \mathrm{~h}$ and rinsed thrice with TBST for 10 min Chemiluminescence was detected with a gel imaging system.

\section{The Expression of Interstitial Phenotype Related Factor SIPR5 mRNA Was Detected by qPCR}

Colonic cancer and normal colon epithelial cell lines were collected, total RNA was extracted by the TRIzol method (TRIzol reagent, Thermo Fisher Scientific, USA;qSYBR Green PCR kit, Shanghai GenePharma, Shanghai, China), RNA concentration was determined with an ultraviolet spectrophotometer, and purity was determined. Total RNA reverse transcription was synthesized in cDNA using a reverse transcription kit. The reaction conditions were $25^{\circ} \mathrm{C}, 5 \mathrm{~min}, 42^{\circ} \mathrm{C}, 30 \mathrm{~min}, 85^{\circ} \mathrm{C}, 5 \mathrm{~min}$ and $4{ }^{\circ} \mathrm{C}$. QPCR was amplified and detected by fluorescence quantitative PCR. QPCR reaction conditions were as follows: pre-denaturation at $95{ }^{\circ} \mathrm{C}$ for $5 \mathrm{~min}, 95^{\circ} \mathrm{C}$ for $5 \mathrm{~s}, 60^{\circ} \mathrm{C}$ for $30 \mathrm{~s}, 72{ }^{\circ} \mathrm{C}$ for $20 \mathrm{~s}$, and $65^{\circ} \mathrm{C}$ for $5 \mathrm{~s}$, for a total of 40 cycles. The relative mRNA expression level of S1PR5 was calculated by $2-\Delta \Delta \mathrm{Ct}$.

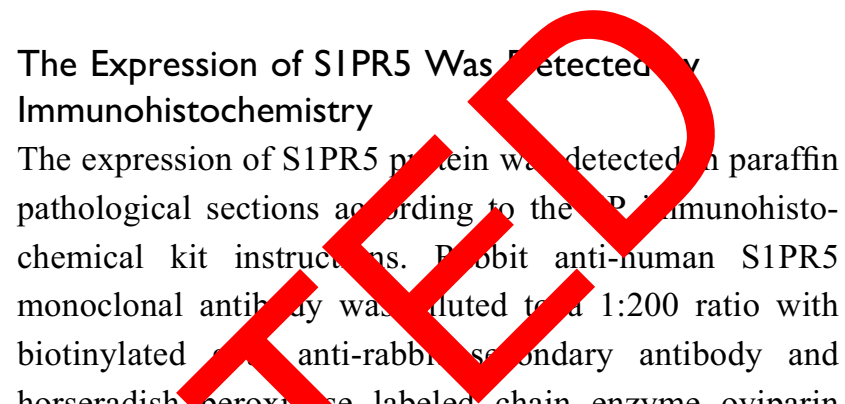
horseradish peroxt e labeled chain enzyme oviparin (triantil $\longrightarrow$ as the 0 inal solution in the kit. After add g DAB reagent to develop color, the rabbit antirab t secondary antibody was stained with hematosin and aled wit neutral resin. Immunohistochemical ctaining at that brown-yellow granules were positive in votoplasm and in vivo. The double-blind method as used to observe the whole field of view in tissue ections. The semi-quantitative integration method was sed to determine the results and the positive location, as follows: (1) number of positive cells: 0 points for no positive cells, $<10 \%$ is 1 point, $10 \% \sim 50 \%$ is 2 points, $>50 \% 50 \%$ is 3 ; (2) the positive intensity of staining, colorless or similar to the background color was 0 points, light yellow was 1 point, tan was 2 points, tan was 3 points. The integrals of (1) and (2) were multiplied; the integral $<4$ was divided into low expression, and the integral $\geq 4$ was divided into high expression. (3) Ki67 index (labeling index, LI). Ten fields of each section were randomly selected. Ki67 positive cells were counted, and the percentage was calculated under a low-power microscope $(\times 200)$. The average value was Ki67LI. As there were multiple fields with different scores in all tablets, the mean values of the largest and smallest were selected for immunohistochemical scoring. Strong staining of the nucleus was positive, weak staining of the nucleus or cytoplasm was negative. Among them, if the number of positive cells was $\geq 10 \%$, it was referred to as high Ki67LI, and if the number of positive cells was $<10 \%$, it was referred to as low Ki67LI. 
A

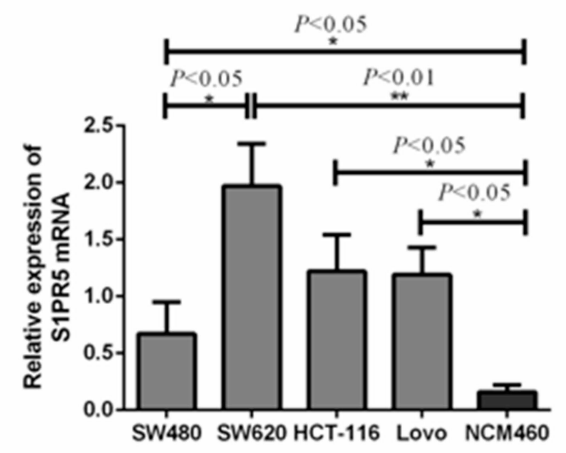

SW480 SW620 HCT-116 Lovo NCM460

B

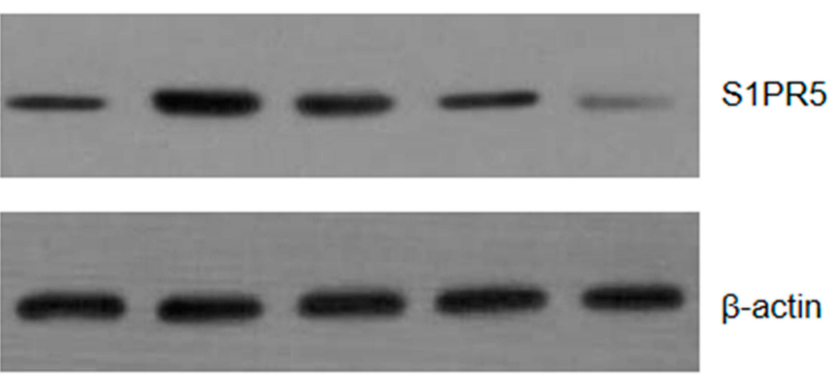

Figure I Expression of SIPR5 mRNA and protein in colon cancer cells and colonic epithelial cells. (A) qRT-PCR; (B) Western blo _tection. between normal colonic epithelial cell line and NCM460, $P<0.05$; ** refers to the difference between normal colon cells and $\mathrm{N} C<60, P<0.0 \mathrm{I}$ ).

\section{Data Processing}

SPSS20.0 was used for statistical analysis. Continuous variables were marked with mean \pm standard deviation, the $t$-test and Mann-Whitney rate or percentage catege ation vàables were marked. The Chi-square est à oner's ex test were mainly used

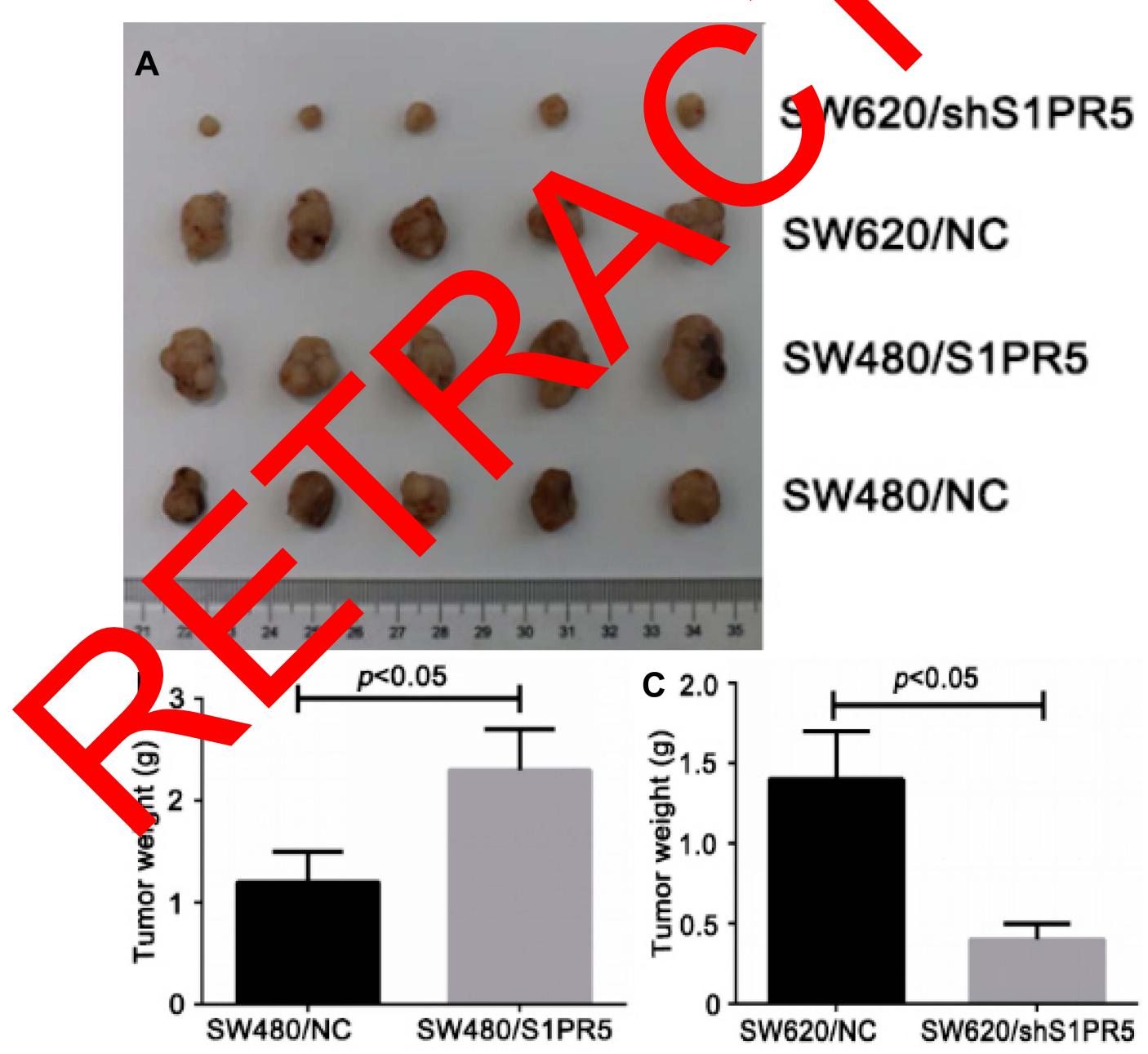

Figure 2 Comparison of tumor weight of nude mice in each group $(n=5)$. (A) Morphology of the skin of the four groups of nude mice after peeling; (B) SIPR5 overexpression promotes subcutaneous tumor growth of SW480 cells; (C) SIPR5 expression knockdown inhibits the growth of subcutaneous tumors of SW620 cells. 


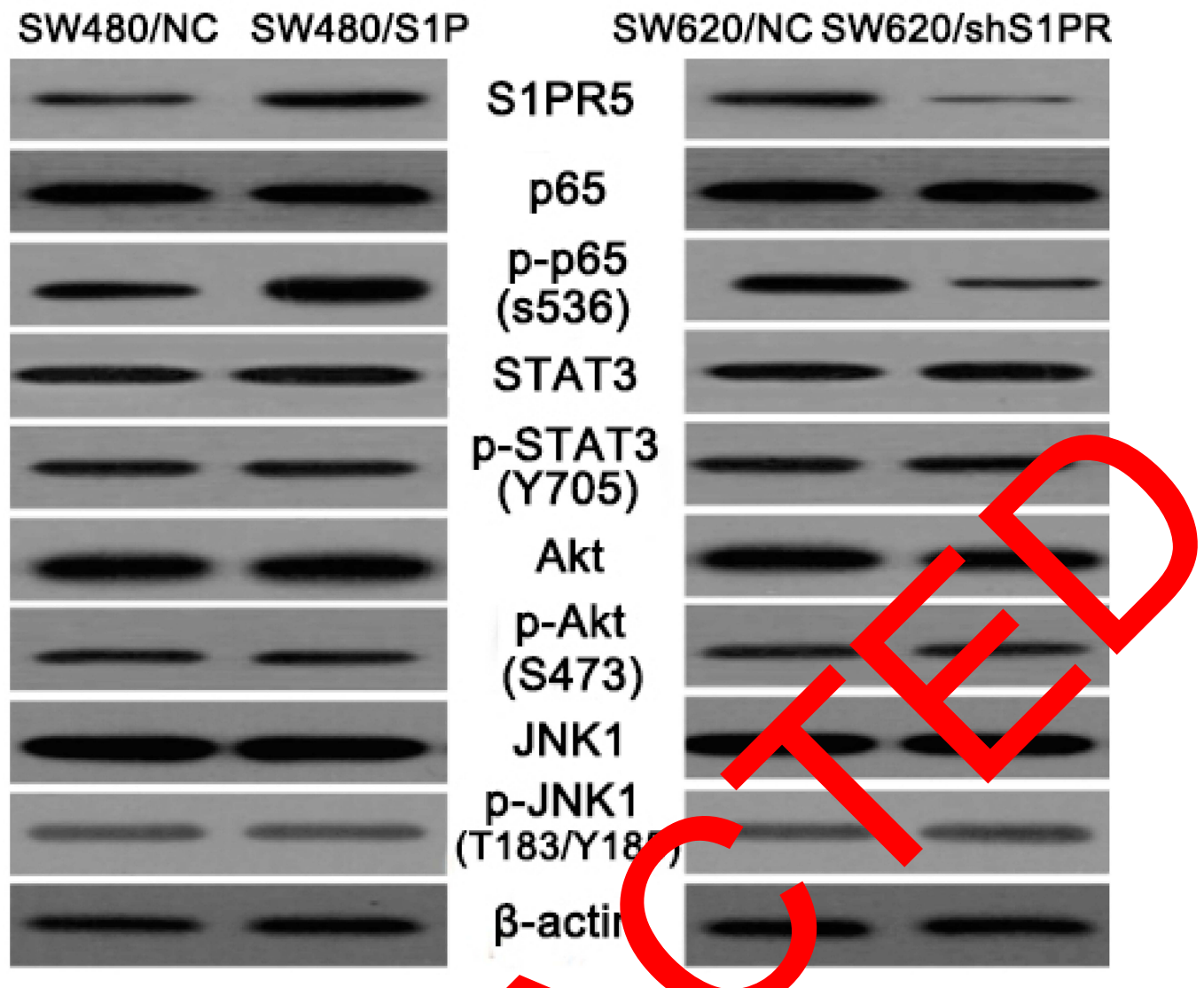

Figure 3 Western blot analysis of the effects of SIPR5 expression on common naling

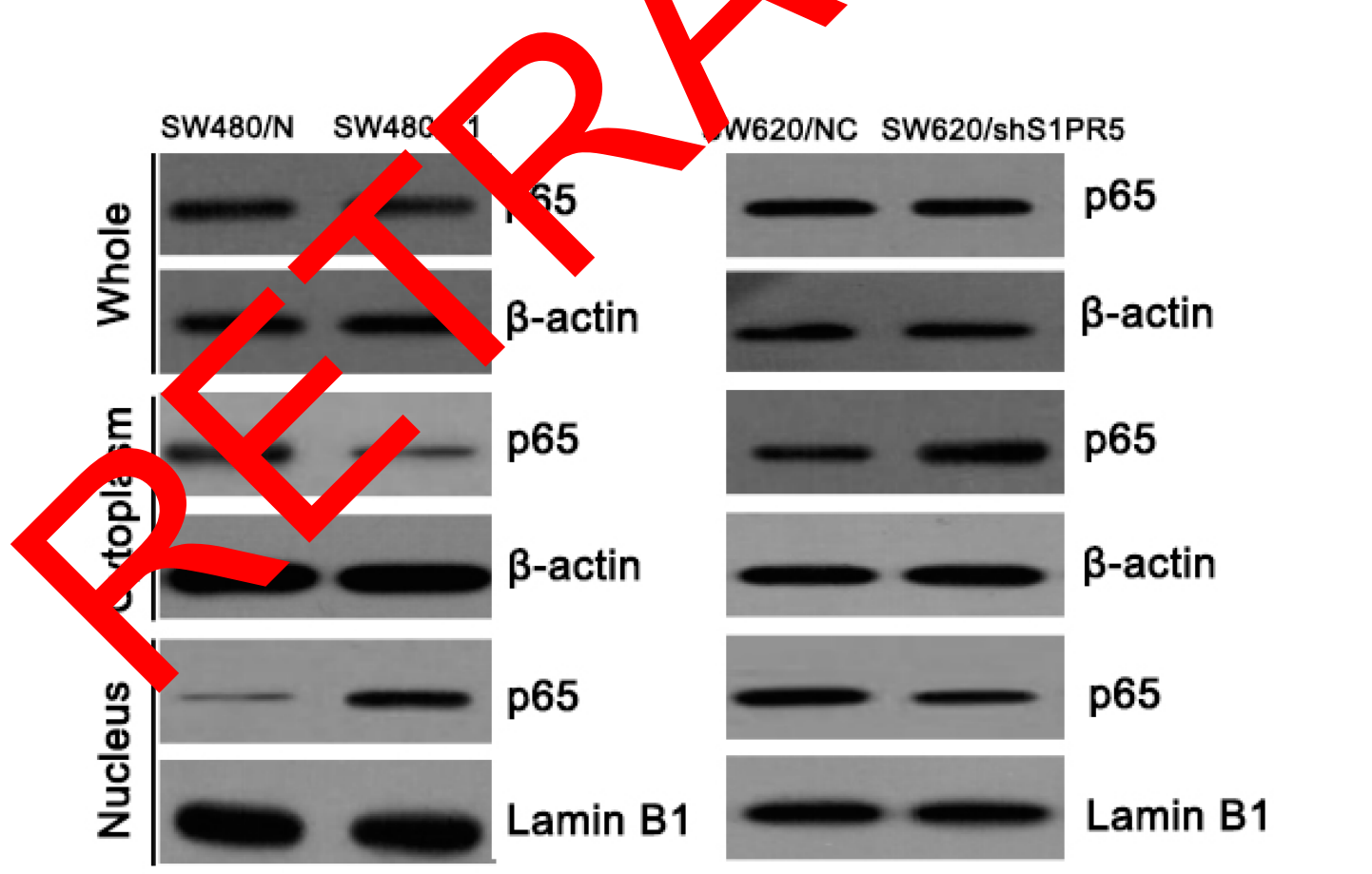

Figure 4 Effects of SIPR5 on cytoplasmic and nuclear p65 levels. 

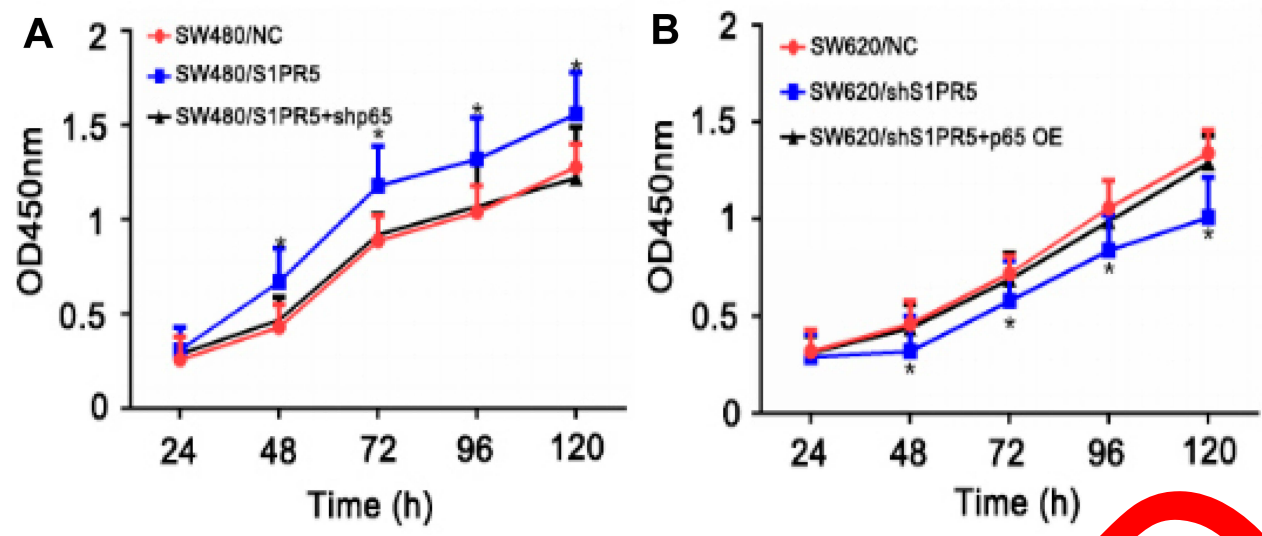

Figure 5 Effect of p65 and SIPR5 intervention on colon cancer cell proliferation. (A) p65 knockdown antagonizes the abilit, SIPR5 to prom proliferation; (B) Overexpression of p65 restores the proliferation ability of colon cancer cells caused by knockdown of $S$ "nR5. Note: *Means that the difference is statistically significant at the same time point as the corresponding control group,

for comparison. $\quad \mathrm{P}<0.05$ was considered statistically significant.

\section{Results and Discussion Expression of SIPR5 in Colon Cancer Cell Lines}

The expression levels of S1PR5 mRNA in four cancer cell lines, SW480, SW620, het-116, and bo, and in normal colonic epithelial cells from the $\mathrm{NCM}$ cell line were detected using qRT-P $C$. I resu showed that the expression of S1PR MRNA all fou colon cancer cell lines was signific thy that of normal colonic epithelial cell es $\left(\mathrm{NCM}^{-}\right)(\mathrm{p}<0.05)$. Among the four colon carer co lines, S1P . 5 mRNA expression was the loy st in SW48 and the highest in SW620 (Figure 1A Western blot also confirmed that the expression of S1 5 pr an in colon cancer cells was lower than $t^{\text {th }}$ now colon mucosal tissues (Figure 1B). The ore, th role a chanism of S1PR5 in colon cancer are in and by down-regulating the expression of $S, 5$ in SW620 cells and up-regulating the expression of $\mathrm{PR} 5$ in SW480 cells.

\section{Tumor Weight of Each Group of Nude Mice}

The nude mouse model was prepared by subcutaneous injection. Tumors were removed and weighed. Tumors of SW480/NC, SW480/S1PR5, SW620/NC, and SW620/ shS1PR5 groups weighed $1.54 \pm 0.1,2.8 \pm 0.4,1.8 \pm 0.2$, and $0.5 \pm 0.1 \mathrm{~g}$, respectively (Figure 2). Based on these tumor volume esults, was foy that S1PR5 promotes the subcut sus tumorig ic dity of colon cancer cells.

\section{Molncular Ro of SIPR5}

f further analyze the potential role of S1PR5 in colon cancer, wo cell lines yere established: the SW480 colon cancer cell with sta $\mathrm{C}$ overexpression of S1PR5, and the SW620 colo cell line knocked out by S1PR5 expression, hich is commonly detected using Western blot in colon cancer. Western blot analysis of the signaling molecules of common signaling pathways, such as AKT, STAT3, JNK, and NF-кB, showed that the change in S1PR5 expression only affected the NF-кB signaling pathway (Figure 3). These results suggest that $\mathrm{S} 1 \mathrm{PR} 5$ may play a role in regulating the NF-кB signaling pathway. The hallmark event of the NF-кB signaling pathway is the translocation of p65 into the nucleus. Therefore, the relationship between S1PR5 and the NF-кB signaling pathway was investigated through evaluation of the distribution of p65 in the cytoplasm and the nucleus.

\section{SIPR5 Regulates P65 Activity in Colon Cancer Cells}

Nucleolar protein is used to support the nuclear envelope and participate in the disintegration and re-formation of the nuclear envelope in the cell cycle. The effects of S1PR5 expression on p65 expression in the cytoplasm and nucleus were detected by WB. In this study, the results showed that the expression of S1PR5 was correlated with the presence of p65 in the nucleus. In S1PR5 knockout cells, p65 levels decreased in the nucleus. However, in S1PR5 overexpressing cells, p65 levels in the nucleus increased, with the difference being statistically significant $(\mathrm{P}<0.05)$ (Figure 4$)$. 


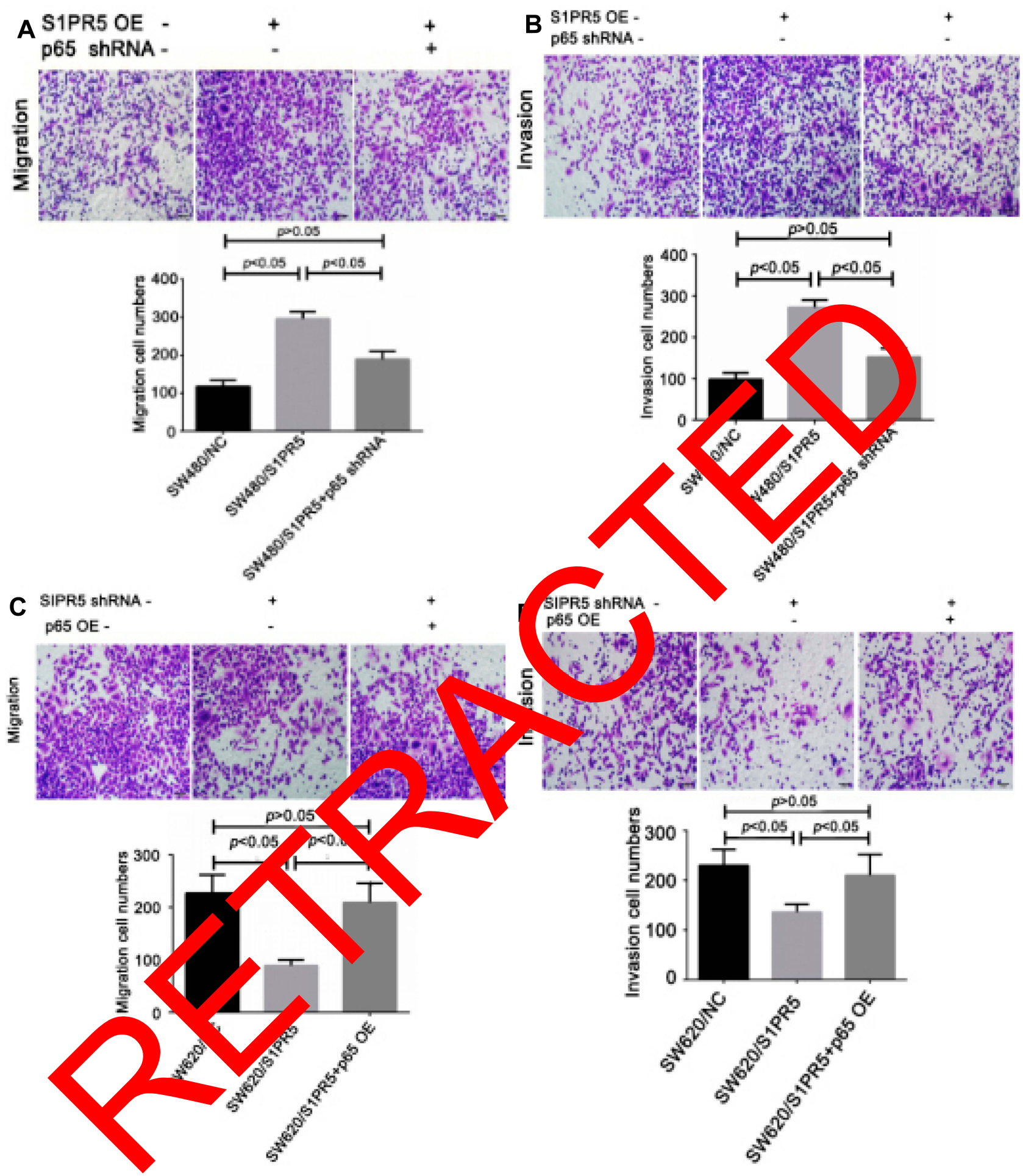

Figure 6 Effects of NF- $\mathrm{kB}$ and SIPR5 on cell migration and invasion in colon cancer $(\times 100)$. (A) SIPR5 overexpression promotes the migration of colon cancer cell line SW480, while 655 knockdown antagonizes the migration of SIPR5 overexpressing cells (left panel shows the control; middle panel shows SIPR5 overexpression; and right panel shows SIPR5 overexpression combined with p65 knockdown); (B) SIPR5 overexpression promotes invasion of the colon cancer cell line SW480, while p65 knockdown antagonizes the pro-invasive effect of SIPR5 overexpression (left panel shows control; middle panel shows SIPR5 overexpression; and right panel shows SIPR5 overexpression combined with p65 knockdown); (C) SIPR5 knockdown inhibits migration of the colon cancer cell line SW620, while p65 overexpression reverses the migration inhibition of SIPR5 knockdown (left panel shows control; middle panel shows SIPR5 expression knockdown; and right panel s SIPR5 expression knockdown combined with p65 expression); (D) SIPR5 knockdown inhibits invasion of the colon cancer cell line SW620, while p65 overexpression reverses the invasion of SIPR5 knockdown (left panel shows control; middle panel shows SIPR5 expression knockdown; and right panel shows SIPR5 expression knockdown combined with p65 expression). 


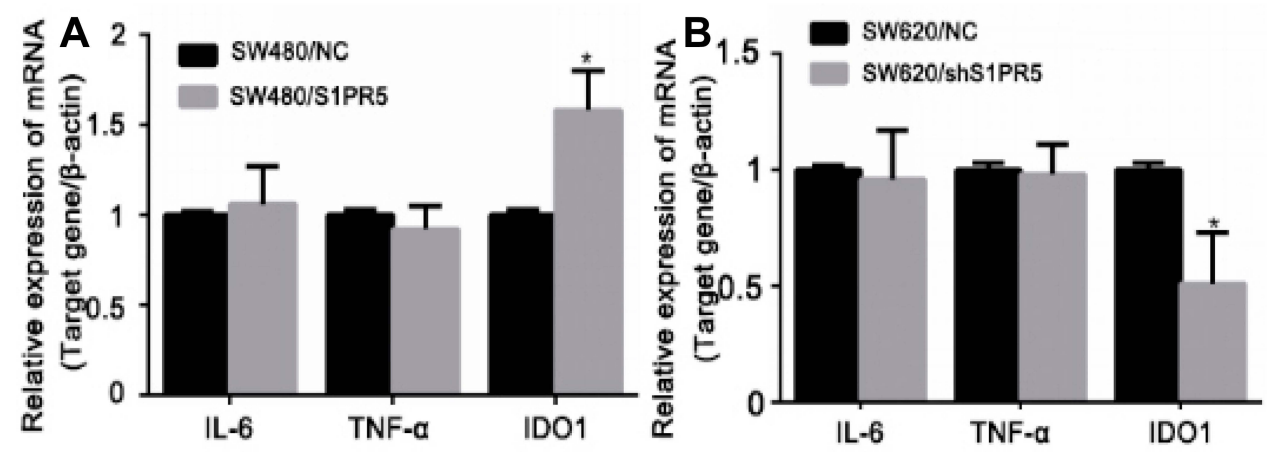

Figure 7 Effect of SIPR5 expression on the expression of NF- $\kappa B$ target genes. (A) SW480 cells; (B) SW620 cells. Note: *Means that the difference was statistically significant, compared with the NC group $(P<0.05)$.

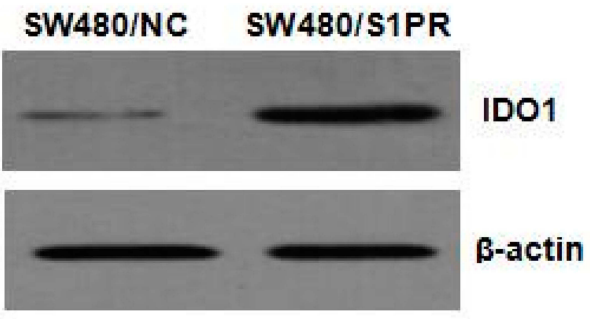

Figure 8 Effect of SIPR5 expression on IDOI protein expression.

\section{Effect of P65 Intervention on} SIPR5-Related Cell Biological Function Furthermore, the relationship between NF $\mathrm{B}$ a $\mathrm{S}$ S1Pl related biological functions was conf aned. T) SW48 cell line, which overexpresses

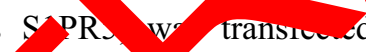
with shRNA p65, and the S R5 knoch wn SW620 cell line was transfected w pu eukaryotic xpression plasmid. The effect of $/ 5$ on the logical function of S1PR5 was evaluat

The CCK-8 Rerim showed that SW480 cells proliferated sionifio 4 after PR5 overexpression, while Sy $80 \mathrm{c}$ ls p re ed after transfection of shRN 065 , y ch did trot differ from SW480 cells in the co group (rrgure 5A). After S1PR5 expression was kn ked down, SW620 cell proliferation was significantly in ibited, and after transfection with p65 eukaryotic expression plasmid, SW620 cell proliferation ability was restored, with no difference between SW620 cells and the control group (Figure 5B). This suggests that p65 is important for S1PR5 as a target.

Transwell experiments showed that after S1PR5 overexpression, the migration and invasion ability of SW480 cells was significantly enhanced, and after transfection with shRNA p65, the proliferation and migration of
SW480 cells decreased. There was no difference between Sw 0 cells and the control group. After S1PR5 expression was knocked down, the migration and invasion abilities of SW620 cells were significantly inhibited, and after transfection with p65 eukaryotic expression plasmid, SW620 cells migrated and invaded with no difference between the SW620 cells and the control group, suggesting that p65 is important for S1PR5 as a target (Figures 6-9).

\section{Screening for Downstream Target Genes and Validation of NF-kB}

$\mathrm{NF}-\kappa \mathrm{B}$ is an important transcription factor that exhibits increased activity in most tumor cells. A variety of carcinogenic factors may promote cell growth by activating the NF- $\mathrm{BB}$ pathway, thereby causing malignant transformation of the cells and promoting tumor cell metastasis. ${ }^{13}$ As a transcription factor, NF- $\kappa$ B plays a biological role mainly by regulating downstream gene expression. Since colon cancer is mostly accompanied by an inflammatory response, it was speculated that NF- $\kappa \mathrm{B}$ promotes the development of colon cancer by regulating the expression of inflammatory factors. Biosignal analysis and literature reviews were used to identify IL-6, TNF- $\alpha$, and indoleamine 2, 3-dioxygenase 1 (IDO1) as 
A
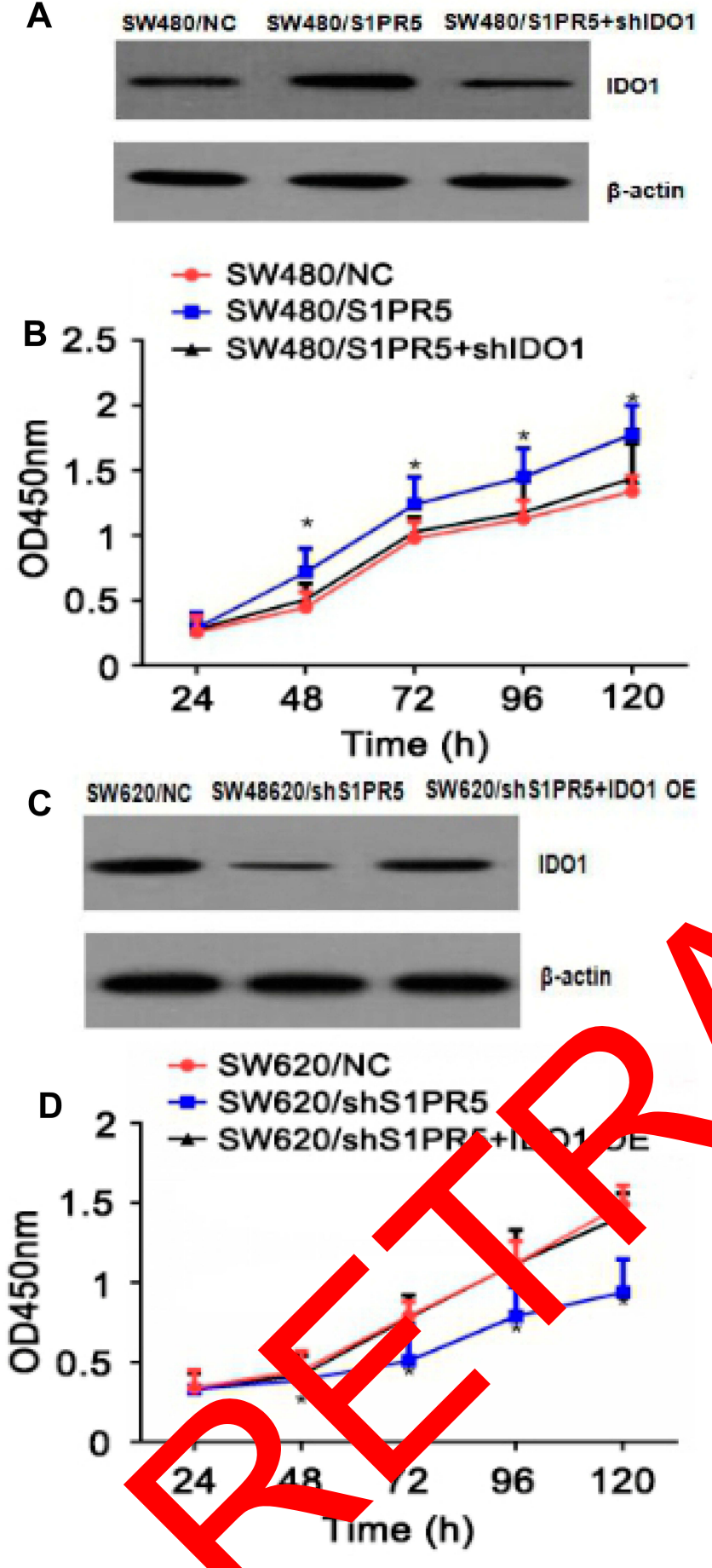

Figure 9 Effects of IDOI an IPR5 on proliferation of colon cancer cells SW480 (A) and SW620 (B). (A) Western blot assay showing increased expression of IDOI in SW480 cells after SIPR5 overexpression; (B) CCK-8 assay results showing that SW480 cells grew faster after SIPR5 overexpression, and SW480 cell growth slowed down after transfection of IDOI shRNA; (C) Western blot assay showing that expression of IDOI in SW620 cells decreased after SIPR5 knockdown; (D) CCK-8 assay results showing that SW620 cells grew slower after SIPR5 knockdown, and SW620 cells grew after transfection with IDOI overexpression plasmid.

downstream effectors of the NF-kB pathway, ${ }^{14,15}$ which are involved in the inflammatory response. These three genes were speculated to be potential target genes for NF- $\mathrm{KB}$ in colon cancer. qRT-PCR was first used to detect the expression of common NF- $\mathrm{kB}$ downstream target genes, including IL family members and IDO1, in SW480/S1PR5 and SW480/shS1PR5 cells (Figures 6 and 7). The results showed that IDO1 expression was consistent with the trend of NF- $\mathrm{kB}$ expression, suggesting that S1PR5 regulates the expression IDO1 through $\mathrm{NF}-\mathrm{\kappa B}$, thereby promoting the proliferation and metastasis of colon cancer. It has been shown previously that IDO1, a cancer gene, is abnormally elevated in various tumors. ${ }^{16}$

\section{IDOI Is an Important Tare an SIPR5 in Colon Cancer}

The expression S1PR5 was und correspor with the expression of IDO1, and s expressio ren was consistent with the chang on NF $B$ expres.onon. IDO1 is a downstream tar ge. of NF- $\mathrm{c}^{\prime}$, which lends the speculation th PR5 is in ve colon cancer. Since IDO1 is reg ated $\mathrm{NF}-\kappa \mathrm{B}$, it would play a role in cancer cell prolifaration, migh on, and invasion. To confirm this hyp resis, the expression of IDO1 was inhibited in SW 80/S1PR5 ells and up-regulated in SW620/ shS 25 cells, d changes in cell proliferation, migration, an on were evaluated.

rexpression of S1PR5 resulted in an increase in 01 levels, as revealed by Western blot, while the CCK-8 assay showed that SW480 cell growth increased gnificantly. Overexpression of S1PR5 in SW480 cells transfected with IDO1 shRNA resulted in a decrease in IDO1 expression levels, as revealed by Western blot, while the CCK-8 assay results showed that SW480 cell growth decreased. There was no difference between the SW480 cells and the control group $(\mathrm{P}>0.05)$ (Figure 12). Knockdown of S1PR5 expression gave rise to a decrease in IDO1 expression, as revealed using Western blot, while the CCK-8 assay results showed that SW620 cell proliferation was significantly inhibited. S1PR5 expressing SW1 cells transfected with IDO1 overexpression plasmid showed a restoration in SW620 cell proliferation ability. No statistically significant $(\mathrm{P}>0.05)$ difference between SW620 and control group cells was observed (Figure 13).

Transwell experiments showed that S1PR5 overexpression caused a significant enhancement in the migration and invasion abilities of SW480 cells, while transfection with IDO1 shRNA caused a decrease in the proliferation and migration abilities of SW480 cells, with no difference between SW480 cells and the control group $(\mathrm{P}>0.05)$. After S1PR5 expression was knocked down, the migration 

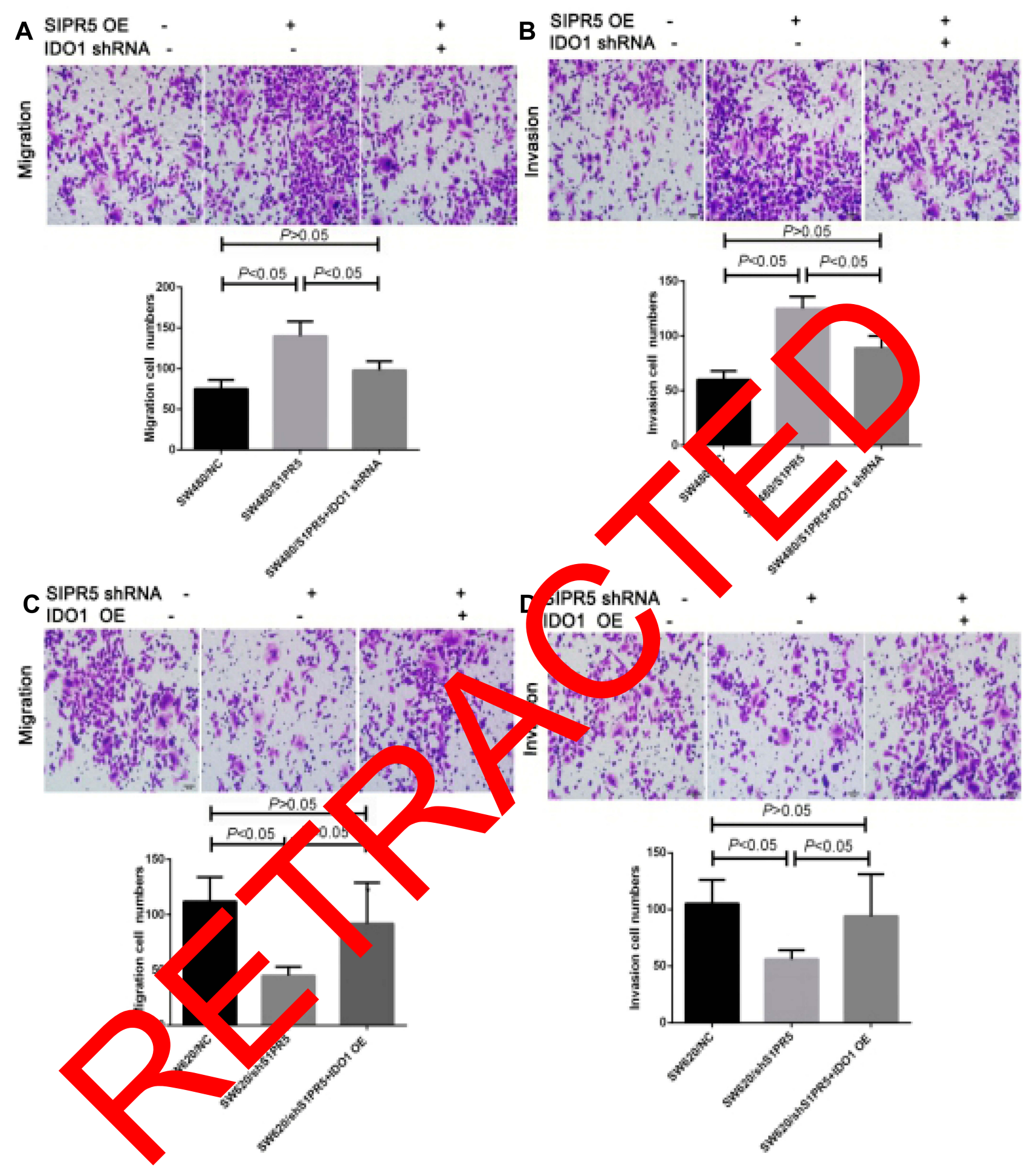

Figure 10 Effect of IDOI and SIPR5 on cell migration and invasion of colon cancer $(\times 100)$. (A) SIPR5 overexpression promotes the migration of SW480 colon cancer cells, while IDOI knockdown antagonizes the migration effect of SIPR5 overexpression (left panel shows control; middle panel shows SIPR5 overexpression; and right panel shows SIPR5 overexpression, with IDOI knockdown); (B) SIPR5 overexpression promotes the invasion of SW480 colon cancer cells, while IDOI knockdown can antagonize the pro-invasive effect of SIPR5 overexpression (left panel shows control; middle panel shows SIPR5 overexpression; and right panel shows SIPR5 overexpression, with IDOI knockdown); (C) SIPR5 knockdown inhibits the migration of SW620 colon cancer cells, while IDOI overexpression can reverse the migration inhibition caused by SIPR5 knockdown (left panel shows control; middle panel shows SIPR5 expression knockdown; and right panel shows SIPR5 expression knockdown, with IDOI expression); (D) SIPR5 knockdown inhibits invasion by SW620 colon cancer cell lines, and IDOI overexpression can reverse the invasion of SIPR5 knockdown (left panel shows control; middle panel shows SIPR5 expression knockdown; and right panel shows SIPR5 expression knockdown, with IDOI expression). 
Table I Expression of IDOI in Colon Cancer and Adjacent Tissues $(n=98)$

\begin{tabular}{|l|l|l|l|}
\hline \multirow{2}{*}{} & \multicolumn{3}{|l|}{ IDOI Expression } \\
\cline { 2 - 4 } & N & P & Positive Rate (\%) \\
\hline Colon cancer tissue $(\mathrm{n}=98)$ & 24 & 74 & 75.5 I \\
Paracancer tissue $(\mathrm{n}=98)$ & 76 & 22 & 22.45 \\
\hline$\chi^{2}$ & \multicolumn{3}{|l}{} \\
$P$ & 20.142 \\
\hline
\end{tabular}

Table 2 Expression of p-p65 in Colon Cancer and Adjacent Tissues $(n=98)$

\begin{tabular}{|l|l|l|l|}
\hline & \multicolumn{3}{|l|}{ P-p65 Expression } \\
\cline { 2 - 4 } & Negative & Positive & $\begin{array}{l}\text { Positive } \\
\text { Rate (\%) }\end{array}$ \\
\hline Colon cancer tissue (n=98) & 17 & 81 & 82.65 \\
Paracancer tissue ( $\mathrm{n}=98)$ & 83 & 15 & 15.3 \\
\hline$\chi^{2}$ & 39.276 & & \\
$P$ & $<0.01$ & \\
\hline
\end{tabular}

Table 3 Correlation Analysis Between SIPR5 and IDOI in Colon Cancer

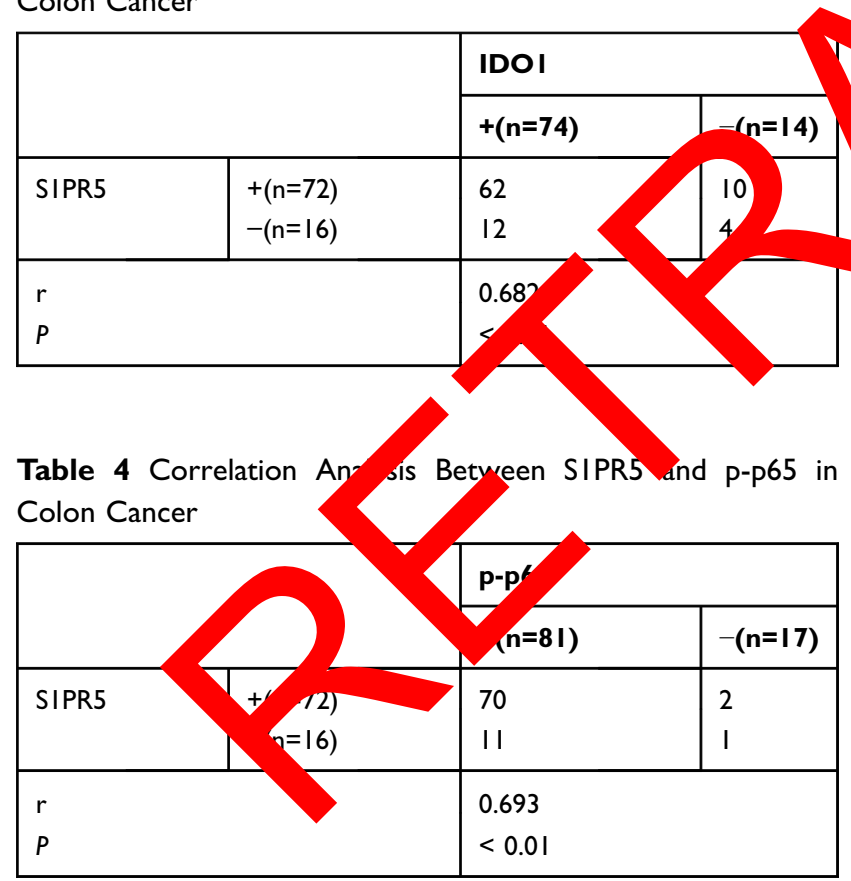

and invasion abilities of SW620 cells were significantly inhibited. Further, after transfection with the IDO1 eukaryotic expression plasmid, SW620 cells migrated and invaded, and no difference was found between SW620 cells and the control group $(\mathrm{P}>0.05)$ (Figures 9 and 10).
IDOI and p-p65 are Highly Expressed in Colon Cancer Clinical Samples, and SIPR5 is Positively correlated with IDOI and $\mathrm{p}$-p65 Expression

Immunohistochemistry was used to detect the expression IDO1 and p-p65 in clinical samples, and their correlation with S1PR5 expression was analyzed. The results showed that IDO1 and p-p65 were highly expressed in the colon cancer samples and correlated with S1PR5 expression (Tables 1-4). IDO1 was mainly expressed in the cytoplasm and could be seen as brown granules ositive ression was judged under the microscope, us the follow criteria: the cell membrane or cytopla $\mathrm{A}$ had ownish-y low particles, and the staining was gnificantly her an the background. p-p65 is mainl xpress in the nuveus, and brown granules indicate $r$ stive ession (F gures 11 and 12).

\section{Expression of IPR5, IDOI, and P-p65 in Sub atareous Tur ors of Colon Cancer in No de Mice}

Afte the subcu heous tumor-bearing nude mice were sacrific tho amors were removed, and Western blot mised to detect the expression levels of S1PR5, 01 , and p-p65 (Figure 13). Consistent with the results from clinical samples, the expression trends of p-p65 and DO1 aligned with the expression trend of S1PR5.

\section{Discussion}

$\mathrm{S} 1 \mathrm{PRs}$ belong to the $\mathrm{G}$ protein-coupled receptor family and are involved in the regulation of almost all important cellular signaling pathways. ${ }^{17}$ Under S1P stimulation or constitutive activation, S1PRs may activate pathways, such as ERK2, JNK, $\mathrm{PI} 3 \mathrm{~K} / \mathrm{p} 38 \mathrm{MAPK}$, and PI3K/AKT/mTOR, through different subunits of the coupled $G$ protein, which further activate YAP, AP-1, and transcription factors, such as STAT3 and NF- $\kappa$ B, in order to promote the expression of effector molecules and exert their biological effects. Consistent with the results of functional studies of S1PRs in tumors, information on the specific mechanism by which S1PRs regulate tumors is also mainly obtained from related studies of S1PR-3. S1PR1 can promote cell proliferation, survival, and migration by regulating multiple signaling pathways, such as Ras/ERK, PI3K/AKT, PI3K/ Rac, STAT3, and PLC. Among them, the positive feedback regulation between S1PR1 and STAT3 is an important mechanism for S1PR1-mediated promotion of tumor progression. Overexpression of S1PR1 can activate STAT3, which can 


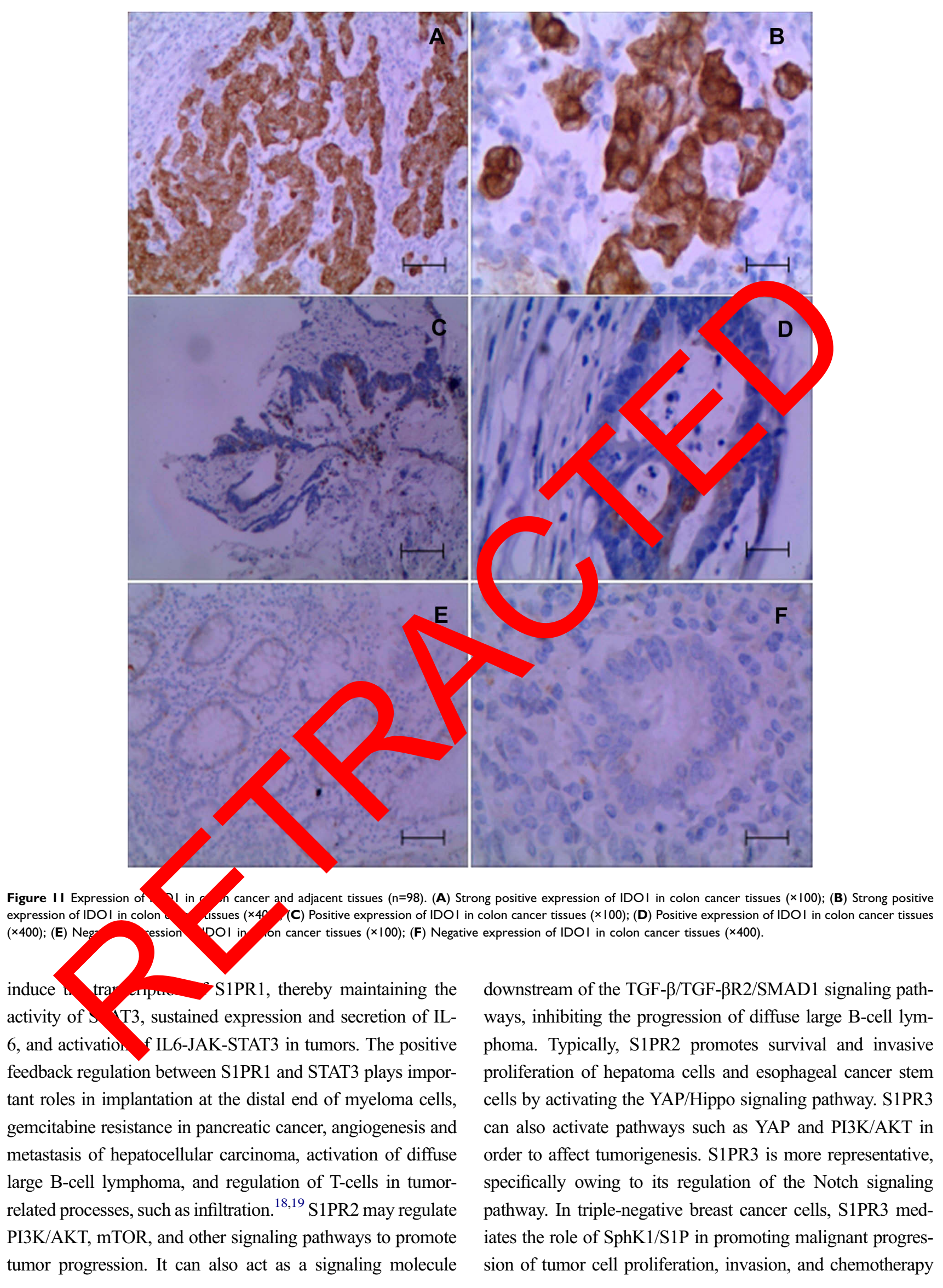




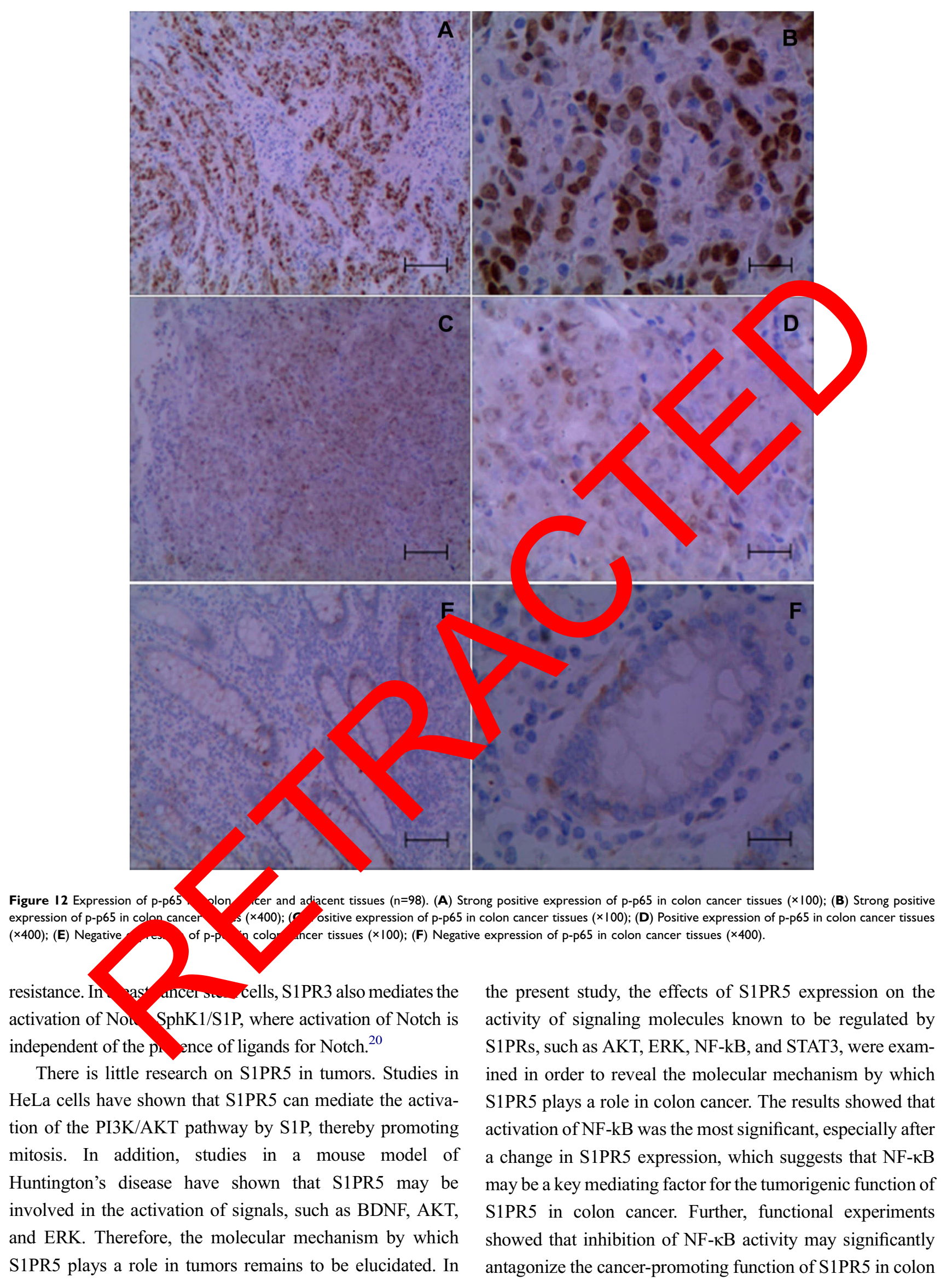




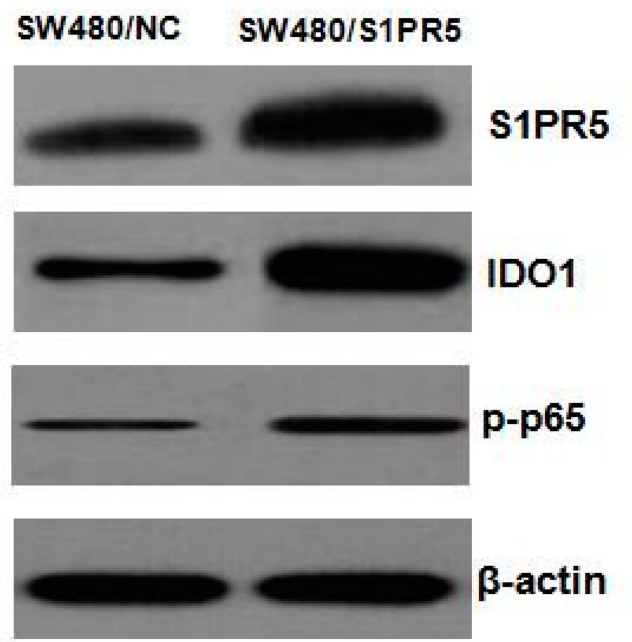

Figure 13 Expression of SIPR5, IDOI, and p-p65 in subcutaneous tumor model of colon cancer in nude mice.
SW620/NC SW620/shS1PR5
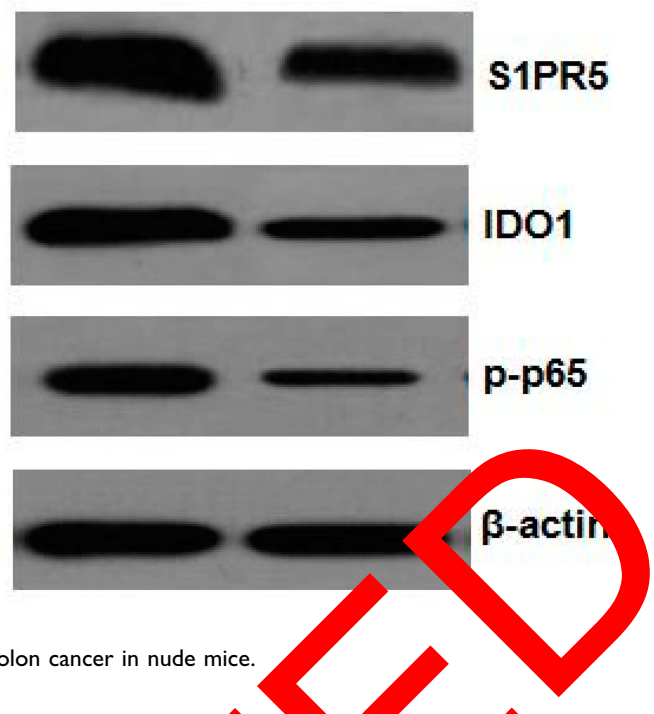

cancer. Therefore, our study confirmed that S1PR5 promotes colon cancer progression mainly by activating NF- $\kappa \mathrm{B}$.

The NF- $\mathrm{KB}$ signaling pathway plays a key role in numerous physiological and pathological processes. It is responsible for regulating the immune system, inflammation, infection, and other stress responses. ${ }^{21-25}$ An abnormal NF$\mathrm{\kappa B}$ signaling pathway is closely related to tumors, $a^{\text {thero- }}$ sclerosis, diabetes, chronic inflammatory diseases, and t major diseases that threaten human life. ${ }^{1,26}$ In most tun abnormal NF- $\kappa$ B signaling is one of the mai ca es, an helps promote tumorigenesis and drug $r$ stance regula ing the expression of genes involved in opt s, invm tumor development, treatment $r$ stance, an ecurrence. In this study, we demonstrated at S TR can act te NF- $\mathrm{kB}$ activity in a classical mar er, and inh rion of NF- $\kappa$ B activity is resistant to the rects of S1PR5 $\mathrm{d}$, he proliferation, migration, and ink on of $c$ on cancer cells, indicating that $\mathrm{NF}-\mathrm{KB}$ mediates the of $\mathrm{S} 1 \mathrm{PR} / \mathrm{M}$ promoting the malignant progr son colon nce This study not only reveals the mo cular me ganism by which S1PR5 promotes tumorigenesis $n$ cancer out also demonstrates that NF- $\mathrm{BB}$ plays an imp ant role in colon cancer; thus, targeting the combination of $\mathrm{S} S \mathrm{R} 5$ and the $\mathrm{NF}-\kappa \mathrm{B}$ pathway may prove to be an effective treatment modality for the inhibition of colon cancer.

IDO1 is one of the rate-limiting enzymes that catalyzes tryptophan catabolism by the kynurenic acid pathway. ${ }^{27-29}$ Abnormal metabolism of tryptophan or IDO1 may cause severe inhibition of the immune system and have serious consequences. Therefore, enhanced tryptophan metabolism is an important mechanism for tumor cell immune escape. In immune and sammato umor croenvironments of colon

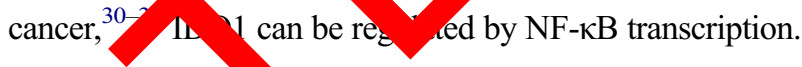

\section{onclusions}

was spec thed that IDO1 may be affected by S1PR5 gulation, si ce NF- $\kappa$ B mediates the function S1PR5. The res con that $\mathrm{S} 1 \mathrm{PR} 5$ may regulate the expression level of IDO1 and be NF- $\mathrm{BB}$ dependent. Knockdown or oven xpression of IDO1 may antagonize or restore, respectively, the effects of S1PR5 overexpression/knockdown on the growth, migration, and invasion of colon cancer cells. Additionally, in colon cancer tissues, high expression levels of S1PR5, NF- $\mathrm{B}$, and IDO1 showed a significant positive correlation with each other. Nucleolar protein supports the nuclear envelope and participates in the disintegration and re-formation of the nuclear envelope in the cell cycle. In summary, this study demonstrated that S1PR5 induces the expression of IDO1 in an NF$\kappa \mathrm{B}$-dependent manner, thereby promoting the malignant progression of colon cancer, and that targeting S1PR5/ $\mathrm{NF}-\kappa \mathrm{B} / \mathrm{IDO} 1$ may help inhibit colon cancer.

\section{Ethical Review}

All of the procedures were carried out in accordance with the Chinese Guidelines for Animal Welfare and Experimental Protocol and were approved by the Animal Care and Use Committee of the Xiangya Hospital, Central South University.

\section{Acknowledgments}

This work was supported by the Natural Science Foundation of Hunan Province (Grant No. 2018JJ2239). 


\section{Disclosure}

The authors report no conflicts of interest in this work.

\section{References}

1. Zhong L, Luo Y, Huang C, et al. Effect of NF-אB decoy on insulin resistance of adipocytes from patients with type 2 diabetes mellitus. Diabetes Metab. 2011;37(6):520-526. doi:10.1016/j.diabet.2011.04.004

2. Pham TT, Talukder AM, Walsh NJ, et al. Clinical and epidemiological factors associated with suicide in colorectal cancer. Supportive Care Cancer. 2018;27(3):617-621.

3. Gu W, Zhu Y, Ye D. Beyond chemotherapy for advanced disease-the role of EGFR and PD-1 inhibitors. Transl Androl Urol. 2017;6 (5):848-854. doi:10.21037/tau.2017.03.92

4. Tabung FK, Steck SE, Ma Y, et al. Changes in the inflammatory potential of diet over time and risk of colorectal cancer in postmenopausal women. Am J Epidemiol. 2017;186(5):21-27. doi:10.1093/ aje/kwx038

5. Dashti SG, Buchanan DD, Jayasekara H, et al. Alcohol consumption and the risk of colorectal cancer in mismatch repair gene mutation carriers. Cancer Epidemiol Biomark Prev. 2017;26(3):366-373. doi:10.1158/1055-9965.EPI-16-0496

6. Patmanathan SN, Wang W, Yap LF, et al. Mechanisms of sphingosine 1-phosphate receptor signalling in cancer. Cell Signal. 2017;34: 66-75. doi:10.1016/j.cellsig.2017.03.002

7. Xie Z, Liu H, Geng M. Targeting sphingosine-1-phosphate signaling for cancer therapy. Sci China Life Sci. 2017;60(6):585-595. doi:10. 1007/s11427-017-9046-6

8. Park SJ, Im DS. Sphingosine 1-phosphate receptor modulators and drug discovery. Biomol Ther (Seoul). 2017;25(1):80-90. doi:10.4062/ biomolther.2016.160

9. Sukocheva OA. Expansion of sphingosine kinase and sphingosin 1-phosphate receptor function in normal and cancer cells: fron membrane restructuring to mediation of estrogen signali-n and stem cell programming. Int J Mol Sci. 2018;19(2):420-4? do1: 3390/ ijms 19020420

10. Delgado A, Martínezcartró M. Therapeutic pote of th tion of sphingosine 1 phosphate receptors. $r$ Me $2016 ; 23$ (3):1-5. doi:10.2174/0929867323666151

11. Pyne S, Adams DR, Pyne NJ. Sphing in phosphate an phingosine kinases in health and disease: cent ac nces. Prog L trid Res. 2016;62:93-106. doi:10.1016/j

12. Huwiler A, Zangemeister-y ake U. The sphing ye 1-phosphate receptor modulator fingol od as a th ${ }^{1}$ apeutic agent. recent findings and new perspectives. rmaco her. 2018;185:34-49. doi:10.10 16/j.pharmthera.2017.11.0

13. Pires BR, Silva P apaB: two sides of the same coin. Genes. 8;9(1): -31. dol. or ones9010024

14. Wang L, ng L, Me Let al. Can ic acid attenuates the autocrine IL-6 in hep cell car the epigenetic silencing of the NF-kB-IL-6-S 3 feedback loop. RSC Adv. 2015;5(65):5295 2-52957. doi:10. Q/C5RA05878C

15. Subedi L, Venkatesan Kim SY. Neuroprotective and anti-inflammatory activities of allyl isothiocyanate through attenuation of JNK/NF- $\mathrm{kB} / \mathrm{TNF}-$ a signaling. Int J Mol Sci. 2017;18(7):1423-1427.

16. Cesario A, Rocca B, Rutella S. The interplay between indoleamine 2,3-dioxygenase 1 (IDO1) and cyclooxygenase (COX)-2 in chronic inflammation and cancer. Curr Med Chem. 2010;18(15):2263-2271. doi:10.2174/092986711795656063

17. Tang HB, Jiang XJ, Wang C, et al. S1P/S1PR3 signaling mediated proliferation of pericytes via Ras/pERK pathway and CAY10444 had beneficial effects on spinal cord injury. Biochem Biophys Res Commun. 2018;498(4):830-836. doi:10.1016/j.bbrc.2018.03.065
18. Lankadasari MB, Aparna JS, Mohammed S, et al. Targeting S1PR1/ STAT3 loop abrogates desmoplasia and chemosensitizes pancreatic cancer to gemcitabine. Theranostics. 2018;8(14):3824-3840. doi:10. $7150 /$ thno. 25308

19. Silva VR, Katashima CK, Bueno Silva CG, et al. Hypothalamic S1P/ S1PR1 axis controls energy homeostasis in middle-aged rodents: the reversal effects of physical exercise. Aging. 2017;9(1):142-155.

20. Wang YC, Tsai CF, Chuang HL, et al. Benzyl butyl phthalate promotes breast cancer stem cell expansion via SPHK1/S1P/S1PR3 signaling. Oncotarget. 2016;7(20):29563-29576. doi:10.18632/ oncotarget.9007

21. Schmitz M, Shaban M, Albert B, et al. The crosstalk of endoplasmic reticulum (ER) stress pathways with NF- $\mathrm{kB}$ : complex mechanisms relevant for cancer, inflammation and infection. Biomedicines. 2018;6 (2):58-69. doi:10.3390/biomedicines60200

22. Hop HT, Arayan LT, Reyes A, et al. Hea ress-modu dinduction of NF- $\mathrm{KB}$ leads to brucellacidal pro-infla atory defense a inst Brucella abortus infection in murine macrophage $\mathrm{d}$ in a mouse todel. $B M C$ Microbiol. 2018;18(1):44-57.

23. Maracle CX, Agca R, Held , et al. Noncano in signaling in microvessels of atherose' stic lesio s associato with inflammation, atheromatous plagy $\mathrm{h}$ he oy and yyocardial infarction. Atherosclerosis. 18;270:3 - doi:10 /6/j.atherosclerosis.2018. 01.032

24. Sahanfirat emis toglu M, Gud DS, et al. Protection by mTOR inhibition on zymosa duced systemic inflammatory response and oxid rosative stres contribution of mTOR/MEK1/ERK1/2/ $\alpha / \mathrm{I \kappa B}-\alpha / \mathrm{NF}-\mathrm{\kappa B}$ signaling pathway. Inflammation. 2018;41 :276-298. doi .1007/s10753-017-0686-2

25. anda MR, Nan IH, Tian W, et al. Regulation of JAK2/STAT3 and N. B signal tro duction pathways; Veronica polita alleviates dextran 018;100(2):296-303. doi:10.1016/j.biopha.2018.01.168

26 CX, Agca R, Helder B, et al. AB0265 non-canonical NF- $\mathrm{kB}$ signaling in microvessels of atherosclerotic lesions in coronary arteries is associated with inflammatory cell infiltration and myocardial infarction. Ann Rheum Dis. 2016;75(2):982-990.

Zhang G, Xing J, Wang Y, et al. Discovery of novel inhibitors of indoleamine 2,3-dioxygenase 1 through structure-based virtual screening. Front Pharmacol. 2018;9(2):277-287. doi:10.3389/fphar. 2018.00277

28. Zhang SN, Liu X, Yang Q, et al. The study of indoleamine 2,3- dioxygenase 1 and its inhibitors. Fudan Univ J Med Sci. 2017;44(1):1-7.

29. Zhai L, Spranger S, Binder DC, et al. Molecular pathways: targeting IDO1 and other tryptophan dioxygenases for cancer immunotherapy. Clin Cancer Res off J Am Assoc Cancer Res. 2015;21(24):54 27-5434. doi:10.1158/1078-0432.CCR-15-0420

30. Muller AJ, Smith C, Chang MY, et al. Abstract 3665: IDO1 is an integrative determinant of tumor-promoting, pathogenic inflammation. Cancer Res. 2014;74(19):3665-3673.

31. Shinde R, Shimoda M, Chaudhary K, et al. B Cell-intrinsic IDO1 regulates humoral immunity to $\mathrm{T}$ cell-independent antigens. J Immunol. 2015;195(5):2374-2382. doi:10.4049/jimmunol.140 2854

32. Wang XF, Wang HS, Wang H, et al. The role of indoleamine 2,3dioxygenase (IDO1) in immune tolerance: focus on macrophage polarization of THP-1 cells. Cell Immunol. 2014;289(2):42-48. doi:10.1016/j.cellimm.2014.02.005

33. Wang C, Mao J, Redfield S, et al. Systemic distribution, subcellular localization and differential expression of sphingosine-1-phosphate receptors in benign and malignant human tissues. Exp Mol Pathol. 2014;97(2):259-265. doi:10.1016/j.yexmp.2014.07.013 


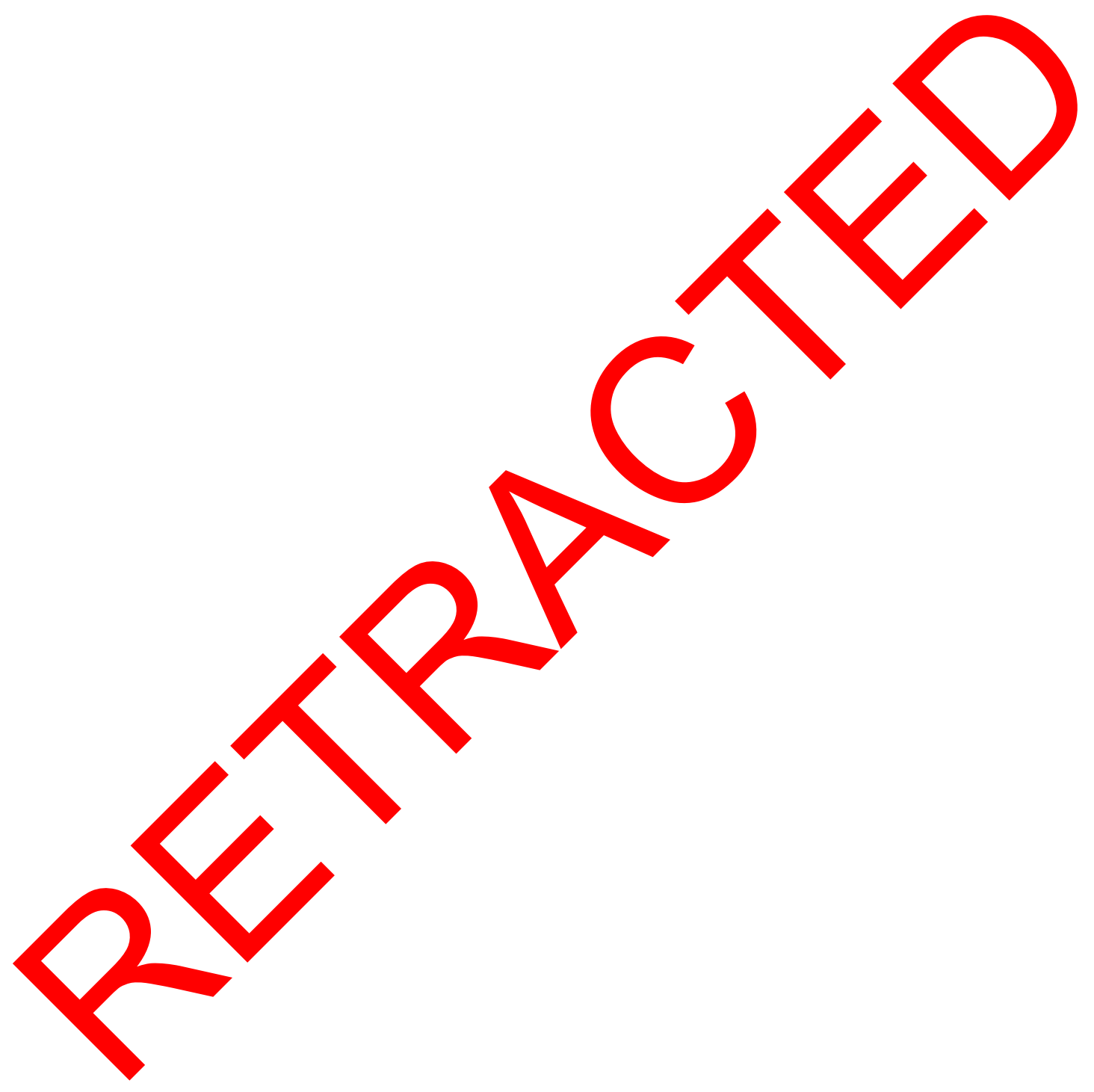

Cancer Management and Research

Dovepress

\section{Publish your work in this journal}

Cancer Management and Research is an international, peer-reviewed open access journal focusing on cancer research and the optimal use of preventative and integrated treatment interventions to achieve improved outcomes, enhanced survival and quality of life for the cancer patient.

The manuscript management system is completely online and includes a very quick and fair peer-review system, which is all easy to use. Visit http://www.dovepress.com/testimonials.php to read real quotes from published authors. 